\title{
The Sino-Italian Collaborative Design Platform: Designing and Developing an Innovative Product Service System
}

\author{
Wei Liu and Yongqi Lou \\ Tongji University, China \\ \{liuwei.dk, lou.yongqi\} @gmail.com
}

\begin{abstract}
This research aims to explore how to bring the richness of collaborative design into the (formal) context of the offices and colleagues. This research went through five stages to design product service systems: 1) product service system analysis, 2) collaborative design, 3) Research on computer supported cooperative work (CSCW) model, 4) User experience research, and 5) Product service system design. Recommendations are given to design and develop interactive collaborative design platforms in the work context. Researchers and designers who are interested in designing and developing rapidly evolving and experiential ICT systems would benefit from learning this research.
\end{abstract}

Keywords: Product service system, collaborative design, user experience, information technologies.

\section{Introduction}

Social innovation requires collaboration between individuals. Collaboration requires individuals working together in a coordinated fashion, towards a common goal. Accomplishing the goal is the primary purpose for bringing the team together. Collaborative platform helps facilitate action-oriented teams working together over geographic distances by providing tools that aid communication, collaboration and the process of problem solving. Additionally, collaborative platform may support project management functions, such as task assignments, time-managing deadlines and shared calendars. The artefacts, the tangible evidence of the problem solving process and the final outcome of the collaborative effort, require documentation and may involve archiving project plans, deadlines and deliverables. This would create a more sustainable working and living environments, which is in line with the theme of this session: Future urban sustainability and social innovation. In this research, by integrating international design resources and the most advanced information technologies (e.g., cloud computing), we aim to achieve a real-time, remote, collaborative and digital product service system from a 'human-centered' perspective. This product service system is called the Sino-Italian collaborative design platform, which includes a set of technological toolkit, intellectual property databases, an easy-to-use crossborder digital prototype and a collaborative design network. This platform connects 
professional design laboratories geographically spread around the world, and supports co-design through seamless digital and physical computer supported cooperative work (CSCW) collaborations. Researchers and designers who are interested in designing and developing rapidly evolving and experiential ICT systems would benefit from learning this research.

\section{Related Work}

In the work context, Keller [8] designed cabinet that helps designers collect and organize their visual material for inspiration. The design makes interaction with digital material more physical by dragging digital images on a table as if they are real objects. It offers a fluent way to add physical material to the digital collection by digitizing and projecting any objects placed on the table. This type of study was followed by several other recent projects in the domain of computer supported collaborative work (CSCW), such as designing an intelligent robot worker that transports goods and samples in semi-public hospital context [11] and designing a shape-changing communication device that facilitates expressive 'knocking' communications between two office workers [16]. Another example is the intelligent reading lamp, which aims to demonstrate ethics and esthetics in products and systems [21]. By moving the hand over the lamp, a 'living light' can be directed onto an object such as a book. This interaction design can fit into both the home and work contexts.

\section{$3 \quad$ Research Objectives}

Our research objective has been to explore how to bring the richness of collaborative design that people currently experience in the experimental context into the (formal) context of their offices and colleagues. This is an interesting challenge that presents itself to developers, designers and researchers.

\section{Approach}

From the beginning and throughout the whole research, digital and physical prototypes that are rich in aesthetic, expressive and experiential quality will be built and tested in real contexts. In the first phases of the project emphasis lies in the exploration of new ways of interacting and new technologies, while later on in the project the focus shifts to applying these new techniques within the domain of collaborative design platform. To ensure a high flow of thoughts, ideas and knowledge, a research through design approach is taken, in which the generation of knowledge and the development of applications go hand in hand. Research through design is used as a form of research to contribute to a design activity [1], [21]. It is recognized as a form of action research, defined as systematic investigation through practical action calculated to devise or test new information, ideas, forms or procedures and to produce communicable knowledge [1], [9]. Action research is an iterative process involving 
researchers and practitioners acting together in a particular cycle of activities [2], [20]. The research through design approach is highly iterative, integrating theory and practice from different fields into working experiential prototypes. These prototypes can be experienced as working artefacts and can be used as research means to demonstrate and explore these theories [14]. Designing and building working prototypes that are rich in experiential quality therefore plays a key role in this approach. The reflection on the action (of designing and building) creates new knowledge. The designing act of creating prototypes is in itself a potential generator of knowledge [6], [17], leading to new design insights and refinement of research issues.

Our research went through the following 5 stages: 1) Product service system analysis: analyzing the characteristics of collaborative products service systems, understanding their information architecture, comparing the advantages and disadvantages of existing systems, referencing these systems for the our design and development. 2) Collaborative design: comparing creative design approach (e.g., brainstorming and exchanging ideas with co-workers through inspirational channels) and other design approaches (e.g., engineering design). 3) Research on computer supported cooperative work (CSCW) model: researching on possible technical solutions of realizing creative collaboration and looking for a new computer supported cooperative work model. 4) User experience research: understanding user behaviors and demands on collaborative product service systems. 5) Product service system design: designing specific use cases, user stories and user interface, developing the whole product service system, e.g., user interface and cloud solutions.

\subsection{Product Service System Analysis}

Products are no longer just products, services not only services. This type of thinking requires new design and development structures, moving people out of their traditional compartments, meeting the needs of an often diverse and evolving group of end-users [3]. Product service systems are designed in highly dynamic network environments, mixing people and parties, models, interests and goals. The design of PSS requires an integrated effort to create the product, the related service and the underlying business model in one comprehensive proposition. For many companies and creative professionals this a relatively new way of working, requiring a more strategic way of thinking. By creating tools and methods, the projects will enable designers to strategically contribute to product service system development. From a conceptual point of view, product service system design requires the creation of experiential value for users. This is a complex process, as the design effort of the sum is greater than that of the individual parts. The user experience research line will look for knowledge, methods and tools to allow the designer to more effectively design these experiences. The intelligence incorporated in functions as an extension to both the product and service components. This may significantly influence the design, testing and prototyping of product-service combinations. The intelligence research line will focus on the optimal application of smart, enabling technology by developing new knowledge, tools and methodologies. 


\subsection{Collaborative Design}

Collaborative design is a generic term, which combines the understanding of the way people design in groups with the enabling technologies of computer networking, and associated hardware, software, services and techniques [4]. Essentially, collaborative design goes beyond building technology itself and looks at how people work within groups and organizations and the impacts of technology on those processes. 'Collaborative' means we have to creatively solve problems and engage in design project activities, management and coordination in both public and private organizations. Techniques for generating and communicating good ideas are needed, both independently and as part of a team. 'Design' means we need a deep understanding of the process of design. We have to understand, advocate and facilitate good design. We have to obtain an understanding of the range and purpose of several design disciplines, strong communication skills and knowledge about the sustainability and economic impact of design thinking.

\subsection{Research on CSCW}

CSCW is a design-oriented academic field that is interdisciplinary in nature and brings together economists, organizational theorists, educators, social psychologists, sociologists, anthropologists and computer scientists, among others [5]. The expertise of researchers in various and combined disciplines help researchers identify venues for possible development. It is an identifiable research field focused on understanding characteristics of interdependent group work with the objective of designing adequate computer-based technology to support such cooperative work [12].

Collaborative design has a great extent of mixing between social scientists and technologists as developers work together to overcome both technical non-technical problems within the same user spaces [13]. For example, many professionals working with collaborative design are computer scientists who have realized that social factors play an important role in the development of collaborative design systems. On the opposite side, many innovation designers and social scientists who understand the increasing role of technology in our social world become 'technologists' who work in research labs to develop cooperative systems [19]. Over the years, researchers have identified a number of core dimensions of collaborative work, including:

- Awareness: individuals designing together need to be able to gain shared knowledge about each other's activities [5].

- Articulation: cooperating individuals to partition design into units, divide it amongst themselves and, after the work is performed, reintegrate it [12].

- Appropriation: how an individual or group adapts a technology to their own particular situation; the technology may be appropriated in a manner completely unintended by the designers [7], [19].

\subsection{User Experience Research}

User experience was considered as an important dimension in designing and developing this product service system. User scenarios in using software and hardware were 
fully considered and compared in the design and development process. Literature research paid specific attention to ergonomic platform, handheld terminals, input and output devices and operating experience. Analysis of creative collaboration helped to summarize the characteristics of user experience of existing systems. Design and development took care of software interface, logical relationships, user interactions, interface visual experience and user testing at different stages of software development.

12 interviews with 12 office workers have taken place at 12 companies, with the number of office workers varying from 10 to 1000 employees. They were young entrepreneurs, wholesalers and office managers. We used basic interviewing technique [9], [10], [15] in the form of face-to-face conversation between researcher and participants. The interview made use of generative toolkit [18]. See Fig. 1 for an impression. Each interview included six steps as described below:

1. Start with an observation of the work context.

2. Ask the participants to work on the toolkit, i.e., select a number of pictures, which express their behaviors and interactions in life and work the best.

3. Participants use the words and the selected pictures to make collages in order to illustrate their personal experiences.

4. Collect stories, trigger discussion and gain reflection from their experiences.

5. Cluster the collages in order to find categories of interaction qualities.

6. Round up discussion and reflection. Audio recordings were taken for the interviews, which

Audio recordings were taken for the interviews, which then later were turned into transcripts. Photographs were also taken during the interviews. In addition, during the interviews, field notes were taken by the researcher to capture informal conversations and contextual observations.

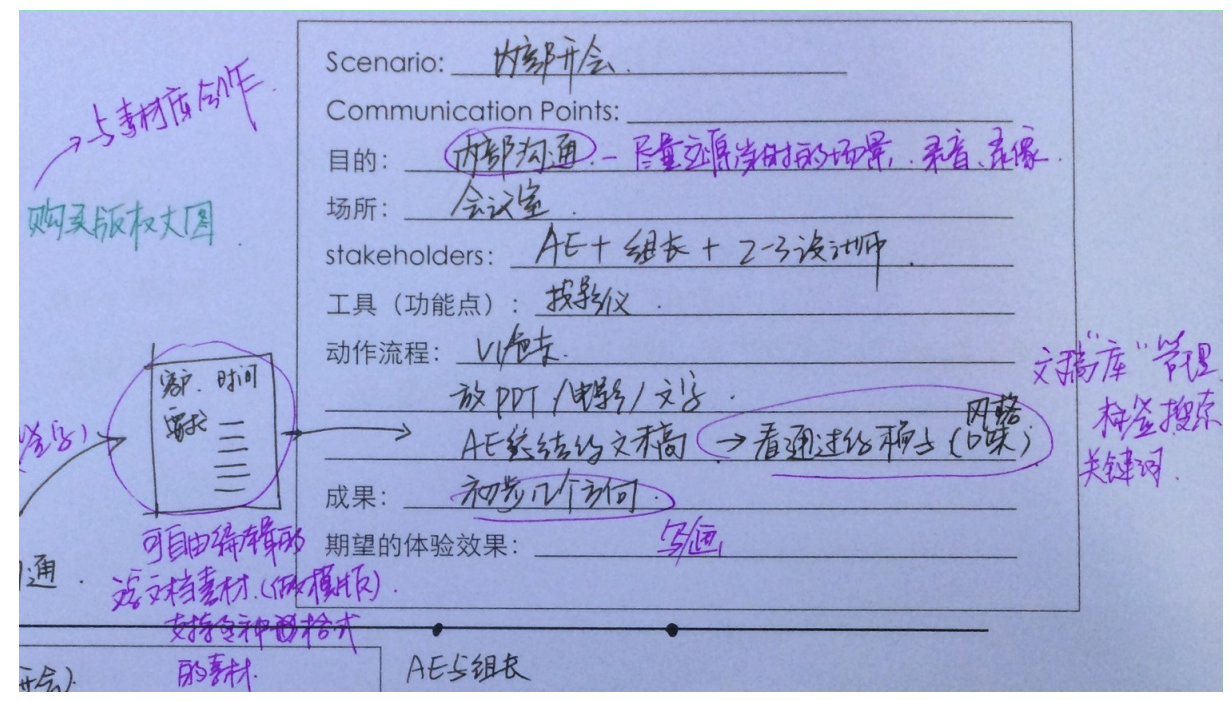

Fig. 1. Example of the filled toolkit 
Qualitative analysis started with all the data (transcripts, collages, field notes and visual materials) gathered in the interviews, followed by communicating the 'selected and distilled insights' [17]. First, each researcher individually read the transcript, marking possibly relevant quotes. Secondly, the researchers consolidated the selection by turning about 80 quotes into explicit interpretations in the format of a statement card. Key part of the format was the interpretation (paraphrase), in which the researchers made explicit in their own words what the quote is saying. Third, the researchers clustered these statement cards into manageable groups, which were labeled and described. Finally, the words and pictures from the collages were also clustered together with the statement cards to help describe the interpretations and convey insights.

\subsection{Product Service System Design}

From the perspective of experience and service to the major stakeholder in-depth product analysis, rendering the overall economic trend graph and cooperation from key areas, key activities, core resources, the promotion of economic operators and other design subsystems. Positioning of the main attributes of specific platforms: design tools, creative showcase, the owners issued a platform for design projects, entrepreneurs seeking venture platform, shared resource platform, global network manufacturing alliance. High low-end platform defines different forms. Consider intertwined stakeholder and design procedures, and specifically designed to select a representative scenario as in the late part of the project implementation.

Platform overall system architecture design and software interface design was performed. On the basis of the first part of the research on the needs and status of the building, products, clothing, media, creative design five typical areas of in-depth analysis. Depending on the stage of the design ideas of user needs further categorized,

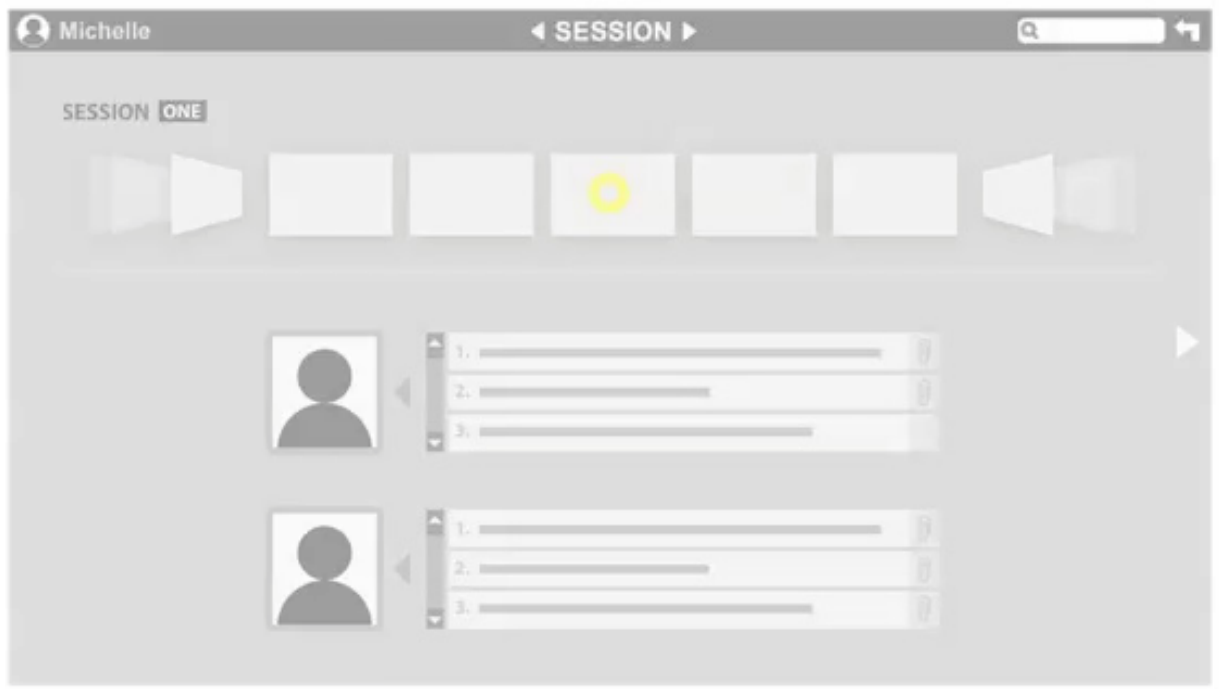

Fig. 2. Example of the user interface design 
and each corresponds to the specific needs of the platform elements were conceived and finishing. Based on the above-depth study on the overall system architecture platform preliminary build. In the software interface has also made the concept, structure and interaction design with features to support the design and creative process. Platform and operating environment of space design and related components of product design was also performed. Domestic and foreign high-tech office space and products for the study, combined with the overall system architecture of the platform design of the physical space in the form of interface platform and the platform for the overall planning and design. See Fig. 2 for an impression of the user interface design.

\section{$5 \quad$ Recommendations}

Based on the results of our research approach, we identified a number of key design recommendations, which are given to design and develop interactive collaborative design platforms in the work context. These recommendations are as follows:

- Support typical user behaviors and meet their expectations

- Optimize styles of interaction

- Match context of use and design tasks

- Adopt iterative design and evaluation process

- Move from product to service system and platform

- Enable cross-platform seamless connection

- Reach ease-of-use and joy-of-use level

- Establish collaborative and multi-tasking user experience

- Apply and innovate modern technologies

- Promote rapid prototyping

\section{Conclusions}

We have gone through five stages on exploring product service system, user experience and technology in the work context. The goals were to explore how to bring the richness of collaborative design into the (formal) context of their offices and colleagues. Our design challenges lie in supporting innovative interactions and apply innovative technologies within the context of collaborative design work.

Our contribution to the existing body of knowledge is to draw attention to IT supported new ways of interacting that will have a great influence on collaborative design context. We gave a number of recommendations, which were then used as criteria to design and develop the experience of user-system interactions. We have a strong focus on studying our users and meeting their wishes in (the early phase of) design. Our findings have implications on the development of the future collaborative design product service systems that should utilize the power and advantages of modern, appropriate and innovative interactions and technologies. Our approach of design and development can also be used in the development of other services and/or tools for conceptualization. 


\section{Future Work}

In the future, we envision going further by completing developing the collaborative design platform prototype in which the design recommendations are implemented. The prototype will also get evaluated based on how it functionally works, how its user interactions fit into the work context and how it can benefit future collaborative design work.

\section{References}

1. Archer, B.: The nature of research. Journal of Codesign (2), 6-13 (1995)

2. Avison, D.E., Lau, F., Myers, M.D., Nielsen, P.A.: Action research. Communications of ACM 42(1), 94-97 (1999)

3. CRISP Platform (2014), http: / / www . crispplatform.nl/projects/pss-101

4. Crowley, T., Milazzo, P., Baker, E., Forsdick, H., Tomlinson, R.: MMConf: an infrastructure for building shared multimedia applications. In: Proceedings of the 1990 ACM Conference on Computer-Supported Cooperative Work, pp. 329-342. ACM Press, New York (1990)

5. Greenberg, S., Marwood, D.: Real time groupware as a distributed system: concurrency control and its effect on the interface. In: Proceedings of the 1994 ACM Conference on Computer Supported Cooperative Work, pp. 207-217. ACM Press, New York (1994)

6. Hoeben, A., Stappers, P.J.: Taking clues from the world outside: Navigating interactive panoramas. Journal of Personal and Ubiquitous Computing 10(2-3), 122-127 (2006)

7. Hughes, J.A., Randall, D., Shapiro, D.: Faltering from ethnography to design. In: Proceedings of the 1992 ACM Conference on Computer-Supported Cooperative Work, pp. 115122. ACM Press, New York (1992)

8. Keller, A.I.: For inspiration only, designer interaction with informal collections of visual material. Doctoral dissertation. Delft University of Technology, Delft (2005)

9. Koskinen, I., Zimmerman, J., Binder, T., Redström, J., Wensveen, S.: Design research through practice, 1st edn. Morgan Kaufmann (2011)

10. Kumar, R.: Research methodology: A step-by-step guide for beginners, 2nd edn. Sage Publications, Thousand Oaks (2005)

11. Ljungblad, S., Kotrbova, J., Jacobsson, M., Cramer, H., Niechwiadowicz, K.: Hospital robot at work: Something alien or an intelligent colleague? In: Proceedings of the ACM 2012 Conference on Computer Supported Cooperative Work (CSCW). ACM Press, New York (2012)

12. Nardi, B.A., Whittaker, S., Bradner, E.: Interaction and outeraction: instant messaging in action. In: Proceedings of the 2000 ACM Conference on Computer Supported Cooperative Work, pp. 79-88. ACM Press, New York (2000)

13. Neuwirth, C.M., Kaufer, D.S., Chandhok, R., Morris, J.H.: Issues in the design of computer support for co-authoring and commenting. In: Proceedings of the 1990 ACM Conference on Computer-Supported Cooperative Work, pp. 183-195. ACM Press, New York (1990)

14. Norman, D.A.: Emotion and design: Attractive things work better. Interactions 9(4), 36-42 (2002) 
15. Rasmussen, M.K., Lehoux, N., Ocnarescu, I., Krogh, P.G.: I'll knock you when I'm ready...: Reflecting on media richness beyond bandwidth and imitation. In: Proceedings of the ACM 2012 Conference on Designing Interactive Systems (DIS), pp. 106-115 (2012)

16. Paton, M.: Qualitative research and evaluation methods (, 3rd edn. Sage Publications, Thousand Oaks (2002)

17. Sanders, L., Stappers, P.J.: Convivial toolbox: Generative research for the front end of design, pp. 224-225. BIS Publishers (2013)

18. Sleeswijk Visser, F., Stappers, P.J., van der Lugt, R., Sanders, E.B.-N.: Contextmapping: Experiences from Practice. Journal of Codesign 1(2), 119-149 (2005)

19. Tang, J.C., Isaacs, E.A., Rua, M.: Supporting distributed groups with a Montage of lightweight interactions. In: Proceedings of the 1994 ACM Conference on Computer Supported Cooperative Work, pp. 23-34. ACM Press, New York (1994)

20. Whyte, W.: Advancing scientific knowledge through participatory action research. Sociological Forum 4(3), 367-385 (1989)

21. Zimmerman, J., Forlizzi, J., Evenson, S.: Research through design as a method for interaction design research in HCI. In: Proceedings of the SIGCHI Conference on Human Factors in Computing Systems. ACM Press, New York (2007) 